\title{
Recent changes in leprosy control
}

\author{
H SANSARRICQ \\ Chief, Leprosy Unit, Division of Communicable Diseases, World \\ Health Organization, Geneva, Switzerland
}

In recent years the limitations of the dapsone-based approach to leprosy control have become increasingly obvious. More recently, it has been found necessary to recommend multidrug regimens which, it is hoped, despite their relative complexity, should result in significant progress in the control of the disease.

This has coincided with an increasing interest in leprosy on the part of governments of many endemic countries. One result of this interest has been the development of concerted efforts in research on leprosy, particularly through the Scientific Working Groups on Immunology of Leprosy (IMMLEP) and Chemotherapy of Leprosy (THELEP), ${ }^{*}$ aimed at the development of better tools for control. Also, many voluntary agencies have strengthened their collaboration with governments and WHO, and have substantially increased their contributions to leprosy activities.

On the whole, leprosy control is now at a turning point at which the secondary prevention strategy must undergo a change from the dapsone monotherapy approach to a multidrug therapy approach, and when research is opening up avenues for developing a primary prevention element to be added, hopefully, to the available armaments against the disease.

\section{Magnitude of the problem}

When expressed in terms of numbers, the leprosy problem does not at first sight seem very impressive. However, there are several factors which give the problem a far higher importance than that of mere statistics. The most important of these factors are the very large populations exposed to the risk of contracting leprosy, the chronicity of the disease, the progressive and permanent disabilities which

* The IMMLEP and THELEP Scientific Working Groups are components of the UNDP/ World Bank/WHO Special Programme for Research and Training in Tropical Diseases. 
occur in a proportion of patients, and the social ostracism to which the patients and even their families are subjected. ${ }^{1}$

Three global surveys of the leprosy situation were made by WHO in $1966,{ }^{2}$ $1972^{3}$ and $1976^{4}$ respectively. Since the last survey, the Organization continues to make efforts to update figures. It is evident that these figures are in many cases approximate and give only a very rough idea of the real situation.

In the 1976 WHO global survey, as shown in Table 1, the total number of leprosy cases existing in the world was estimated to be 10,595,000. This figure does not differ significantly from the estimates derived from previous surveys, which were 10,876,000 and 10,407,200 in 1966 and 1972 respectively.

The estimated total of 10 to 11 million leprosy cases has only an indicative value. However, it is doubtful whether a higher estimate would better reflect the true situation, for reasons given in an earlier publication. ${ }^{5}$

Table 1. Estimated leprosy cases by WHO regions (1975)

\begin{tabular}{lr}
\hline \multicolumn{1}{c}{ WHO region } & No. of cases \\
\hline Africa & $3,500,000$ \\
Americas & 400,000 \\
Eastern Mediterranean & 160,000 \\
Europe & 25,000 \\
South-East Asia & $4,510,000$ \\
Western Pacific & $2,000,000$ \\
\cline { 2 - 2 } Total & $10,595,000$ \\
\hline
\end{tabular}

\section{The classical strategy for leprosy control}

\subsection{ELEMENTS OF STRATEGY}

In the 1950's, it was believed that a secondary prevention approach based on dapsone monotherapy of all infectious cases would, by reducing the reservoir of infection, result in the control of the disease. Leprosy control programmes were based on early case-finding, follow-up of contacts, and prolonged chemotherapy of patients by dapsone, both to limit transmission of the infection in the community and to prevent the disabilities that characteristically occur in various forms of leprosy. This strategy, which was recommended by $\mathrm{WHO},{ }^{6-9}$ has been adopted during the last 30 years in virtually all endemic countries. Dapsone is safe and inexpensive. However, the treatment of paucibacillary cases requires 3-5 years and lepromatous patients must be treated for life, thus resulting in poor 
patient compliance with self-administered treatment. Thus, in many countries, it proved operationally very difficult to mount and sustain field operations, including the two main elements of case-detection and prolonged chemotherapy, on a sufficiently wide scale to make a significant impact on the problem.

In view of the difficulties inherent in the secondary prevention strategy, attempts were made to add to the dapsone-based approach a primary prevention component, i.e. protection of the exposed individuals particularly by a vaccine. In the absence of a vaccine derived from Mycobacterium leprae, BCG was tested for its preventive effect against leprosy in large-scale prospective trials in Uganda, Burma, Papua New Guinea and India. Long-term follow-up of the study subjects in these trials indicates that $\mathrm{BCG}$ is capable of protecting against leprosy to a variable degree. Whereas the study in Uganda indicated that the overall protection was as high as $80 \%$, the other three studies showed that the overall protection was only moderate, ranging from $28 \%$ to $46 \%{ }^{\circ}{ }^{10}$ Therefore, BCG by itself cannot be a very effective tool against leprosy, and the need to develop a highly effective vaccine remains.

\subsection{ACHIEVEMENTS}

The present achievements summarized below are approximately those corresponding to the period during which the secondary prevention strategy for leprosy control based on dapsone monotherapy has been applied.

\subsubsection{Registered cases}

(a) Present information. When the latest figures of registered cases for each country available in the WHO leprosy unit (October 1982) are compiled they lead to the total by continent shown in Table 2 . Thus, there are at present more than $5,300,000$ leprosy patients registered in the world.

(b) Increase in the number of registered cases. Table 3 shows the increase in the number of registered cases worldwide compared to the first WHO global survey (1966). The total number of cases of leprosy known in the world has increased substantially. The increase is almost 2,500,000, i.e. 88\%, between 1966 and 1982 .

Table 4 shows the changes in the number of registered cases over the same period for each continent.

These figures reveal the following important points.

(a) In Africa the number of known cases is lower now than in 1966 by 406,860, i.e. a decrease of $23 \cdot 7 \%$. Such a decrease results partly from the release from control of a substantial number of patients.

(b) In Asia the increase in registration has been dramatic: 2,800,000 more cases on the registers in 1982 than in 1966 (306.8\% increase). However, the increase took place mainly between the 1976 WHO survey and the 1982 compilation: $1,882,838$ registered cases in 1976 and 3,724,400 in 1982. In fact, this 
Table 2. Registered leprosy patients by continent (1982)

\begin{tabular}{lccrc}
\hline \multicolumn{1}{c}{ Continent } & $\begin{array}{c}\text { No. of } \\
\text { countries } \\
\text { surveyed }\end{array}$ & $\begin{array}{c}\text { Estimated } \\
\text { population } \\
\text { (millions) } \\
\text { around 1978* }\end{array}$ & $\begin{array}{c}\text { No. of } \\
\text { registered } \\
\text { patients }\end{array}$ & $\begin{array}{c}\text { Known case } \\
\text { prevalence } \\
\text { per 1,000 }\end{array}$ \\
\hline Africa & 48 & 415 & $1,305,272$ & $3 \cdot 14$ \\
Americas & 40 & 587 & 267,549 & $0 \cdot 46$ \\
Asia (excl. USSR) & 33 & 2,385 & $3,724,400$ & $1 \cdot 56$ \\
Europe & 19 & 771 & 16,616 & $0 \cdot 02$ \\
Oceania & 15 & 22 & 13,509 & $0 \cdot 61$ \\
Total & 155 & 4,180 & $5,327,346$ & $1 \cdot 27$ \\
\hline
\end{tabular}

* World Health Statistics, Annual 1981. Geneva, 1981.

Table 3. Increase in registered leprosy cases in the world

\begin{tabular}{lccc}
\hline & $\begin{array}{c}\text { No. of } \\
\text { countries or } \\
\text { territories } \\
\text { reporting }\end{array}$ & $\begin{array}{c}\text { No. of } \\
\text { registered } \\
\text { cases }\end{array}$ & $\begin{array}{c}\text { Increase when } \\
\text { compared with 1966 } \\
\text { WHO global survey }\end{array}$ \\
\hline 1966 WHO global survey & 151 & $2,831,775$ & - \\
1972 WHO global survey & 124 & $2,887,481$ & $+55,706(+1 \cdot 96 \%)$ \\
1976 WHO global survey & 148 & $3,598,167$ & $+766,392(+27 \cdot 06 \%)$ \\
$\begin{array}{l}\text { Latest available information } \\
\text { in WHO in October 1982 }\end{array}$ & 155 & $5,327,346$ & $+495,571(+88 \cdot 13 \%)$ \\
\hline
\end{tabular}

Table 4. Changes in number of registered leprosy cases by continent (from 1966 WHO global survey and 1982 WHO information)

\begin{tabular}{lrr}
\hline Continent & \multicolumn{2}{l}{$\begin{array}{c}\text { Increase/decrease in number of registered } \\
\text { cases and corresponding percentage }\end{array}$} \\
\hline Asia & $+2,808,875$ & $(+306 \cdot 8 \%)$ \\
Africa & $-406,860$ & $(-23 \cdot 7 \%)$ \\
Americas & $+89,736$ & $(+50 \cdot 4 \%)$ \\
Europe & -8 & $(-0.05 \%)$ \\
Oceania & $+3,828$ & $(+39 \cdot 5 \%)$ \\
\hline
\end{tabular}


increase results to a great extent from new registrations made in India during the same period: 1,320,000 registered cases in 1974 (1976 WHO global survey) and $2,800,000$ in $1982,{ }^{11}$ and from the inclusion of 200,000 (an approximation) known cases $^{12}$ reported by The People's Republic of China, which had not been included in the 1976 WHO global survey.

\subsubsection{Treated cases}

The figures reported in the 1976 WHO global survey showed, for four WHO regions, average proportions of treated cases varying from $71 \%$ to $86 \%$, and average proportions of regularly treated patients in three regions from $42 \%$ to $53 \%$.

\subsubsection{Cases released from control}

The information on these is particularly scarce and inaccurate. Based on the 1976 WHO global survey, an attempt had been made to estimate the number of cases released from control annually. The estimate was of 120,000 to 150,000 . If it is assumed that the release of patients from control has continued at the same level, it may tentatively be concluded that between 1 and $1 \frac{1}{2}$ million leprosy patients have been released from control in the last decade.

Although the global impact of leprosy control has not been impressive, there are a few countries or areas where control activities were conducted in a well-organized and sustained manner over periods of 10 years or more and comparable evaluations have been possible. In such programmes reductions in prevalence of up to $80 \%$ or more were achieved, but a parallel decline in incidence was not observed..$^{5,13}$

\section{Recent changes}

\subsection{PROBLEMS RECENTLY ARISEN}

\subsubsection{Resistance of Mycobacterium leprae to dapsone}

A major problem in leprosy in recent years has been resistance of $M$. leprae to dapsone. The first cases of $M$. leprae resistance to dapsone were proven by the mouse footpad method in Malaysia in $1964 .{ }^{14}$ Over the past 15 years secondary dapsone resistance has been reported with increasing frequency among the patients at risk, that is, multibacillary patients subjected to dapsone monotherapy. The number of countries where dapsone resistance is prevalent is now probably more than 25 spread throughout the world, and the prevalence is steadily increasing in many countries. ${ }^{15}$ 
When lepromatous patients relapse with $M$. leprae secondarily resistant to dapsone, they can infect their contacts with these resistant bacilli, and those contacts who subsequently develop clinical leprosy will have primary resistant disease. Thus, primary resistant leprosy can occur in any form of the disease. Primary resistance to dapsone was proven for the first time in 1977, and subsequent studies show that its prevalence appears to be increasing at a faster pace than that of secondary resistance. ${ }^{15}$

\subsubsection{Persisting M. leprae}

In 1974 it was demonstrated that microbial persistence, a feature of tuberculosis and other infectious diseases, is also a feature of lepromatous leprosy. ${ }^{16}$

\subsection{RECENT CHANGES IN CHEMOTHERAPY OF LEPROSY}

In recent years the introduction of a few new drugs, and particularly rifampicin, has improved the prospects for better treatment. Nevertheless, the high cost and comparatively greater toxicity of newer drugs have limited their wide application in the field. The main drugs with bactericidal activity against $M$. leprae are rifampicin (high bactericidal activity), ethionamide and protionamide (intermediate bactericidal activity), dapsone and clofazimine (both with low bactericidal activity).

Secondary resistance of $M$. leprae has, up to now, been reported ${ }^{17,18}$ in 7 patients treated for approximately 4 years with rifampicin monotherapy and in a small number of patients who had received 5 years of ethionamide monotherapy. ${ }^{19}$ As for clofazimine, despite its widespread use, only 1 proved case of resistance has as yet been reported..$^{20}$

Microbial persistence has been observed in patients treated with rifampicin for 5 years, ${ }^{21}$ and with clofazimine for 10 years..$^{22}$

As early as 1976, in view of the problem of secondary resistance of M. leprae to dapsone, the WHO Expert Committee on Leprosy had recommended that all active cases of multibacillary leprosy be treated with at least two effective antileprosy drugs, including rifampicin. ${ }^{23}$ However, relatively few countries and individual centres have introduced multidrug therapy as a routine practice in their leprosy control programmes.

Because of the growing threat resulting from the increase of secondary and primary resistance to dapsone, as well as of the need to prevent resistance to other drugs, a WHO Study Group on Chemotherapy of Leprosy for Control Programmes was convened in October $1981,{ }^{15}$ in order to define effective chemotherapeutic regimens that were practicable under field conditions. The Study Group proposed standard regimens for all categories of patients in two groups: multibacillary and paucibacillary. The regimens are based on the supervised administration of monthly doses of rifampicin. In multibacillary 
patients the treatment also includes a supervised monthly dose of clofazimine and self-administered daily clofazimine and dapsone. This regimen is to be given for at least 2 years. In paucibacillary patients monthly rifampicin and daily self-administered dapsone are to be given for 6 months.

The Study Group also recognized that so far no drug alone appears to be capable of eliminating persisting $M$. leprae. The possibility that combinations of drugs may be able to eliminate such persisting organisms is currently under investigation in THELEP-controlled field trials.

To prevent the further increase of dapsone resistance and the emergence of resistance to other drugs, the Study Group recommendations should be implemented as soon, as widely and as accurately as possible. If combinations of bactericidal drugs appropriately designed according to the Study Group recommendations are not put into practice: (a) the problem of secondary and primary resistance to dapsone will continue to increase, and (b) resistance to other drugs will emerge and spread.

As a result, until new drugs become available (which will require at least another decade) the leprosy problem will become unmanageable.

In view of the seriousness of the situation, WHO is giving top priority to the implementation of these Study Group recommendations.

It is obvious that no improvement in the efficacy of therapeutic regimens can increase the efficiency of leprosy control if operational aspects are not improved at the same time. The Study Group reviewed the relevant problems related to case-detection, drug delivery and case-holding. The most urgent needs are related to three areas: (a) adequate additional training of all categories of personnel involved in leprosy control, (b) reorganization of leprosy control activities, and (c) mobilization of additional financial resources.

\section{Other needs and prospects}

\subsection{NEED FOR IMMUNOPROPHYLACTIC METHODS}

Present and future treatment methods may be able to solve the problems of resistance to dapsone and other antileprosy drugs, and the problem of persisters, but the need for arduous case-finding and case-holding activities would remain. Adequately trained personnel, sufficient financial resources and good logistics would still have to be provided. Therefore, the development of a tool for primary prevention, i.e. a vaccine of good protective value, would be an invaluable asset.

Such a vaccine may even be a sine qua non for effective leprosy control. Even after potent drug regimens have been put into use, one fears that their epidemiological impact will not be as great as one would wish. In those programmes based on dapsone monotherapy and conducted under the best possible conditions, there was a substantial reduction in prevalence but little 
decrease in incidence, suggesting that before infectious cases receive treatment they have already spread infection with Mycobacterium leprae among a large proportion of their contacts. It seems likely that the use of more potent chemotherapeutic methods, even if it reduces the infectious period of lepromatous cases by a few months as compared to dapsone monotherapy, would not greatly affect the spread of $M$. leprae in the community. However, such a hypothesis remains to be investigated.

If it were only to overcome the difficulties related to rigorous case-finding and case-holding, we would still need an effective vaccine against leprosy. This is the main objective of the IMMLEP programme, and work on such a vaccine is progressing satisfactorily. We believe that it may be possible to launch field trials for the IMMLEP vaccine in the next few years and have results after about 10 years.

\subsection{NEED FOR IMPROVED DIAGNOSTIC TOOLS}

In view of what has just been discussed, a test to identify individuals incubating lepromatous leprosy would be of great value. Some of the tests currently being developed by the IMMLEP SWG may meet this need. Such individuals could then be put under close surveillance or even given prophylactic treatment. They could also benefit from the immunological conversion resulting from the method recently proposed by Convit.

\subsection{IMMUNOTHERAPY}

Recently, Convit ${ }^{24}$ reported that in leprosy patients consistently Mitsuda-negative, the repeated inoculation of a mixture of heat-killed $M$. leprae and living BCG results in clinical, histopathological and immunological changes towards the tuberculoid end of the spectrum. If these results are confirmed, this would be a significant contribution to the treatment of infectious cases and hence to the secondary prevention of the disease.

\section{Conclusion}

The implementation of the secondary prevention strategy for leprosy control based on dapsone monotherapy had to face many difficulties. The main global results obtained during the period of the dapsone monotherapy approach may be summarized as follows:

(a) Worldwide. More than 5 million leprosy cases out of an estimated total of about 10 million existing cases are now under treatment. It can be estimated that from 1 to $1 \frac{1}{2}$ million leprosy patients have been released from control during the last decade. 
(b) Under favourable circumstances reductions of prevalence of $80 \%$ were achieved in a few countries or areas.

The shortcomings of dapsone monotherapy have been increasingly realized over the last 15 years. A new approach to secondary prevention of leprosy through multidrug therapy of all cases has been recently recommended by WHO. The contribution of the THELEP Scientific Working Group to the development of the newly recommended regimens has been essential, clearly demonstrating transfer of the results of research to control efforts. For the first time the results of worldwide research efforts, stimulated and coordinated at the global level, have been translated into important changes in the strategy for leprosy control.

However, in the long term, primary prevention methods, the most important being an effective vaccine, are an essential need in an effective strategy for leprosy control. In addition, immunological tools which would allow the identification of individuals at high risk of developing lepromatous leprosy will be of great help.

In any case, it is unlikely that conclusions on the efficacy of a vaccine will be available within the next decade, or that new potent drugs can be developed.

Therefore, for the years to come, and despite the shortcomings and limitations of the secondary prevention approach, the implementation of effective chemotherapeutic regimens based on combinations of bactericidal drugs is a must if we do not want the leprosy problem to become unmanageable and the gains made so far to be lost. Consequently, in the WHO leprosy programme for the next quinquennium top priority has been given to the implementation of multidrug therapy.

\section{References}

${ }^{1}$ Sansarricq H. The Kellersberger Memorial Lecture, 1981. The general situation of leprosy in the world. Ethiop med J, 1982; 20: 89-106.

2 Bechelli LM, Martinez Dominguez V. The leprosy problem in the world. Bull WHO, 1966; 34: 811-26.

3 Bechelli LM, Martinez Dominguez V. Further information on the leprosy problem in the world. Bull WHO, 1972; 46: 523-36.

${ }^{4}$ WHO. Leprosy. Wkly Epidem Rec, 1979; 54: 17-23.

${ }_{5}^{5}$ Sansarricq H. Leprosy in the world today. Lepr Rev, 1981; 52 (Suppl 1): 15-31.

6 WHO Technical Report Series No. 71, 1953. (First report of the WHO Expert Committee on Leprosy.)

7 WHO Technical Report Series No. 189, 1960. (Second report of the WHO Expert Committee on Leprosy.)

${ }^{8}$ WHO Technical Report Series No. 319, 1966. (Third report of the WHO Expert Committee on Leprosy.)

9 WHO Technical Report Series No. 459, 1970. (Fourth report of the WHO Expert Committee on Leprosy.)

${ }^{10}$ WHO Special Programme for Research and Training in Tropical Diseases. Report of the 6th meeting of the IMMLEP Scientific Working Group (SWG), 7-9 June 1982 (in press).

11 WHO Regional Office for South-East Asia, Regional Committee, 35th Session, Provisional 
agenda item 9. India. Control and prevention of leprosy in the context of primary health care. WHO Regional Committee document SEA/RC35/TD/IP4, 30 July 1982. (Country information paper for the Technical Discussions.)

12 Li Huan Ying. China. In Review of the Country Situation in Tuberculosis and Leprosy Research. (Report of the Scientific Group on Tuberculosis and Leprosy Research convened by the WHO Regional Office for the Western Pacific, Manila, Philippines, 1-5 March 1982), pp. 1-2.

13 Nebout M. La lutte antilépreuse en R.C.A. Résultats obtenus. Acta Le prol (Geneva), 1982, No. 86-87, pp. 15-22.

14 Pettit JHS, Rees RJW. Sulphone resistance in leprosy. An experimental and clinical study. Lancet, 1964; 2: 673-4.

15 WHO Technical Report Series No. 675, 1982. (Report of a WHO Study Group on the Chemotherapy of Leprosy for Control Programmes.)

16 Waters MFR, Rees RJW, McDougall AC, Weddell AGM. Ten years of dapsone in lepromatous leprosy: clinical, bacteriological and histological assessment and the finding of viable leprosy bacilli. Lepr Rev, 1974; 45: 288-98.

17 Hastings RC, Jacobson RR. Rifampin-resistant leprosy. Health cooperation papers, 1981, No. 1, pp. 47-54.

18 Grosset AJ. Personal communication, 1982.

19 Pattyn SR, Rollier MT, Rollier R, Verdoolaeghe-van Loo G. Sensibilité envers la dapsone, la sulfamethoxypyridazine et l'éthionamide de Mycobacterium leprae provenant de malades traités par ces substances. Int J Lepr, 1975; 43: 356-63.

20 Warndorff-van Diepen T. Clofazimine-resistant leprosy, a case report. Int J Lepr, 1982; 50: 139-42.

21 Rees RJW, Waters MFR, Pearson JMH, Helmy HS, Laing AB. Long-term treatment of dapsone-resistant leprosy with rifampicin: clinical and bacteriological studies. Int $J$ Lepr, 1976; 44: 159-69.

22 Rees RJW. Personal communication, 1982.

23 WHO Technical Report Series No. 607, 1977. (Fifth Report of the WHO Expert Committee on Leprosy.)

${ }^{24}$ Convit J, et al. Immunotherapy with a mixture of Mycobacterium leprae and BCG in different forms of leprosy and in Mitsuda-negative contacts. (Submitted for publication in the Int $J$ Lepr.) 